\title{
Vitreous Seeding, Choroid and Sclera Involvement in Retinoblastoma Patients
}

\author{
Dr. Himanshu Jodhani
}

\begin{abstract}
Vitreous seeding, Choroid and Sclera Involvement in Retinoblastoma patients is the aim of the study. This study has been conducted in the M\&J Western Regional Institute of Ophthalmology, Civil Hospital, Ahmedabad, Gujarat between the period of January 2013 to December 2014.In this study 40 cases were included. A detailed histopathological examination was done. Choroid involvement is most common in retinoblastoma patients while scleral involvement is least common.
\end{abstract}

Keywords: Retinoblastoma, Vitreous seeding, choroidal involvement, scleral involvement

\section{Introduction}

Retinoblastoma is a rare eye tumor of childhood that arises in the retina and represents the most common intraocular malignancy of infancy and childhood. It may occur at any age but most often it occurs in younger children, usually before the age of two years. The incidence is 1 in 15,000 20,000 live births. In $60 \%$ of cases, the disease is unilateral and the median age at diagnosis is two years. Of these cases, $15 \%$ are hereditary. Retinoblastoma is bilateral in about $40 \%$ of cases with a median age at diagnosis of one year. All bilateral and multifocal unilateral forms are hereditary.

Leukocoria (white reflection in the pupil) and strabismus are the most frequent clinical manifestations of retinoblastoma. Leukocoria is initially inconstant, visible only at certain angles and under certain light conditions. This sign may be seen on flash photography. Strabismus, when present, becomes rapidly constant, reflecting impairment of the vision. These signs are still all-too-often overlooked and justify an ophthalmological consultation with ocular fundus examination. Some other signs may be observed, including iris rubeosis, hypopyon, hyphema, buphthalmia, orbital cellulitis, and exophthalmia. Some children with retinoblastoma may have no symptoms. Screening in case of familial history or dysmorphic syndrome with a 13q14 deletion may lead to diagnosis of retinoblastoma. Most affected children are diagnosed before the age of five years.

\section{Pathology}

Retinoblastoma is characterized histopathologically by malignant neuroepithelial cells (retinoblasts) that develop within the immature retina. The retinoblasts typically appear to have a large basophilic nucleus and scanty cytoplasm. Cellular necrosis, intralesional calcification and sleeve growth surrounding feeding retinal blood vessels are frequent associations, especially in larger tumors. In some cases, tissue differentiation occurs, often producing Flexner-Wintersteiner rosettes or Homer Wright rosettes. Retinoblastoma has a strong tendency to invade the optic nerve and choroid and extend out of the globe via either the optic nerve or scleral emissary canals.

\section{Materials and Methods}

This study has been conducted in the M\&J Western Regional Institute of Ophthalmology, Civil Hospital, Ahmedabad, Gujarat between the period of January 2013 to December 2014.In this study 40 cases were included. A detailed histopathological examination was done. Thorough clinical examination was done. A detailed history was taken from parents. Relevant medical and surgical history was obtained.Under the ocular examination following parameters were recorded:

1. Visual acuity: if child was co-operative

2. Anterior segment examination: on torch light/ on slit lamp if child allows

3. Posterior segment examination: (with direct and indirect ophthalmoscopy.)

4. B-scan USG (if fundus is not visible)

5. Routine Investigation of the patient (hemogram, ESR, S.HIV, S.HBsAg, RBS, Bl.urea, S.creatinine, urineroutine \& micro)

6. MRI to rule out optic nerve and extraocular spread

7. Whole eyeball was sent for histopathological examination

\section{Results}

This study has been conducted in the M\&J Western Regional Institute of Ophthalmology, Civil Hospital, Ahmedabad between the period of January 2014 to March 2015. There were 24 male children and 16 female children. Age distribution of patients is given in table no. 1 below:

\begin{tabular}{|c|c|}
\hline Age of patient & Number of patients \\
\hline$<1 \mathrm{yr}$ & $9(22.5 \%)$ \\
\hline $1-3$ yrs. & $17(42.5 \%)$ \\
\hline $4-6$ yrs. & $12(30 \%)$ \\
\hline$>6$ yrs. & $2(5 \%)$ \\
\hline Total & 40 \\
\hline
\end{tabular}

Vitreous, choroid and scleral involvement was present in following number of patients as shown in table no. 2

Table 2

\begin{tabular}{|c|c|c|}
\hline & Present & Absent \\
\hline Vitreous seeding & $29(72.5 \%)$ & 11 \\
\hline Choroidal involvement & $32(80 \%)$ & 8 \\
\hline Scleral involvement & $12(30 \%)$ & 28 \\
\hline
\end{tabular}




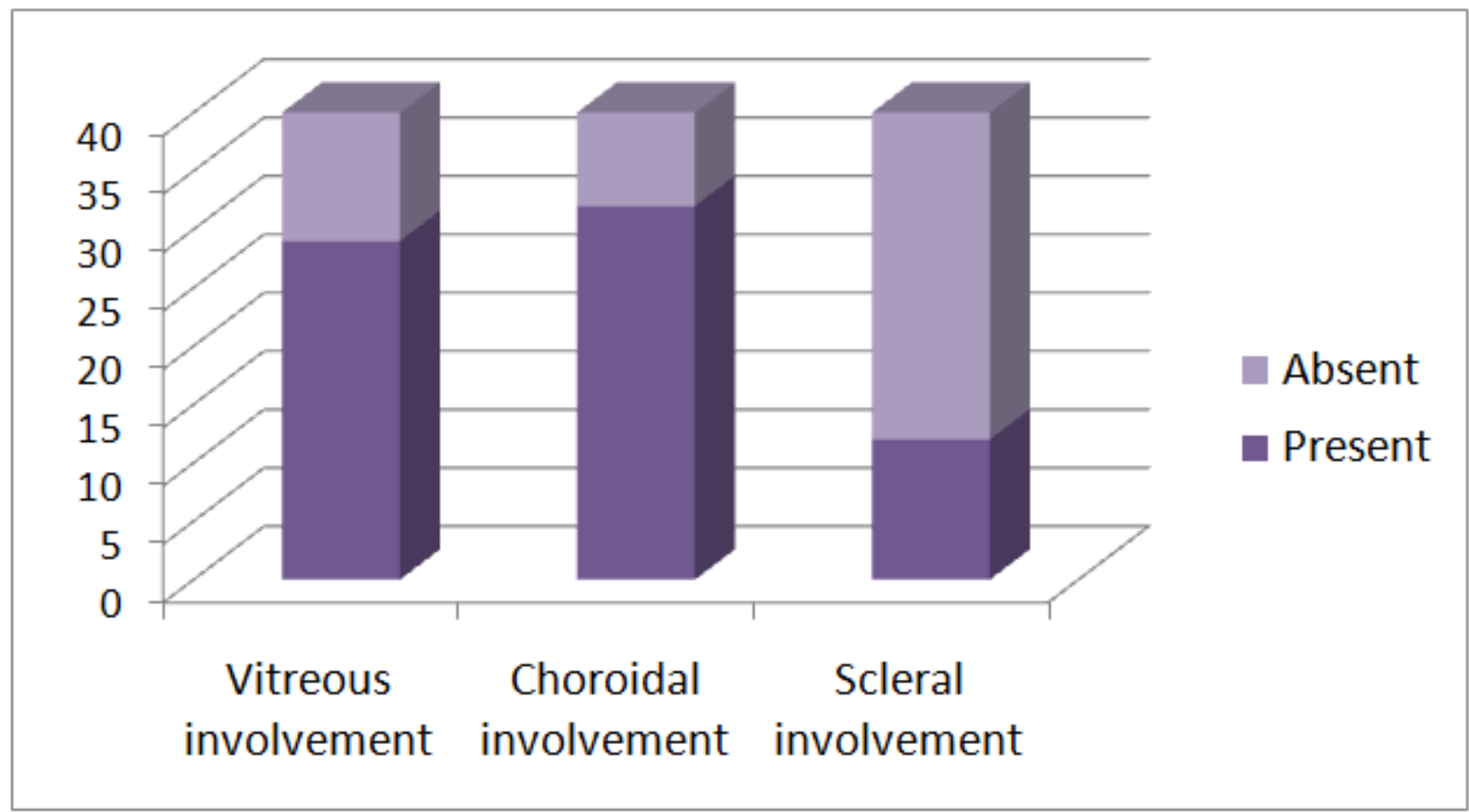

Figure 1

Multiple sites were involved as shown in table no. 3 .

Table 3

\begin{tabular}{|c|c|}
\hline Involvement & Total number of patients \\
\hline Vitreous + Choroid & $26(65 \%)$ \\
\hline Choroid + Sclera & $11(27.5 \%)$ \\
\hline Vitreous + Sclera & $10(25 \%)$ \\
\hline Vitreous + Choroid + Sclera & $10(25 \%)$ \\
\hline
\end{tabular}

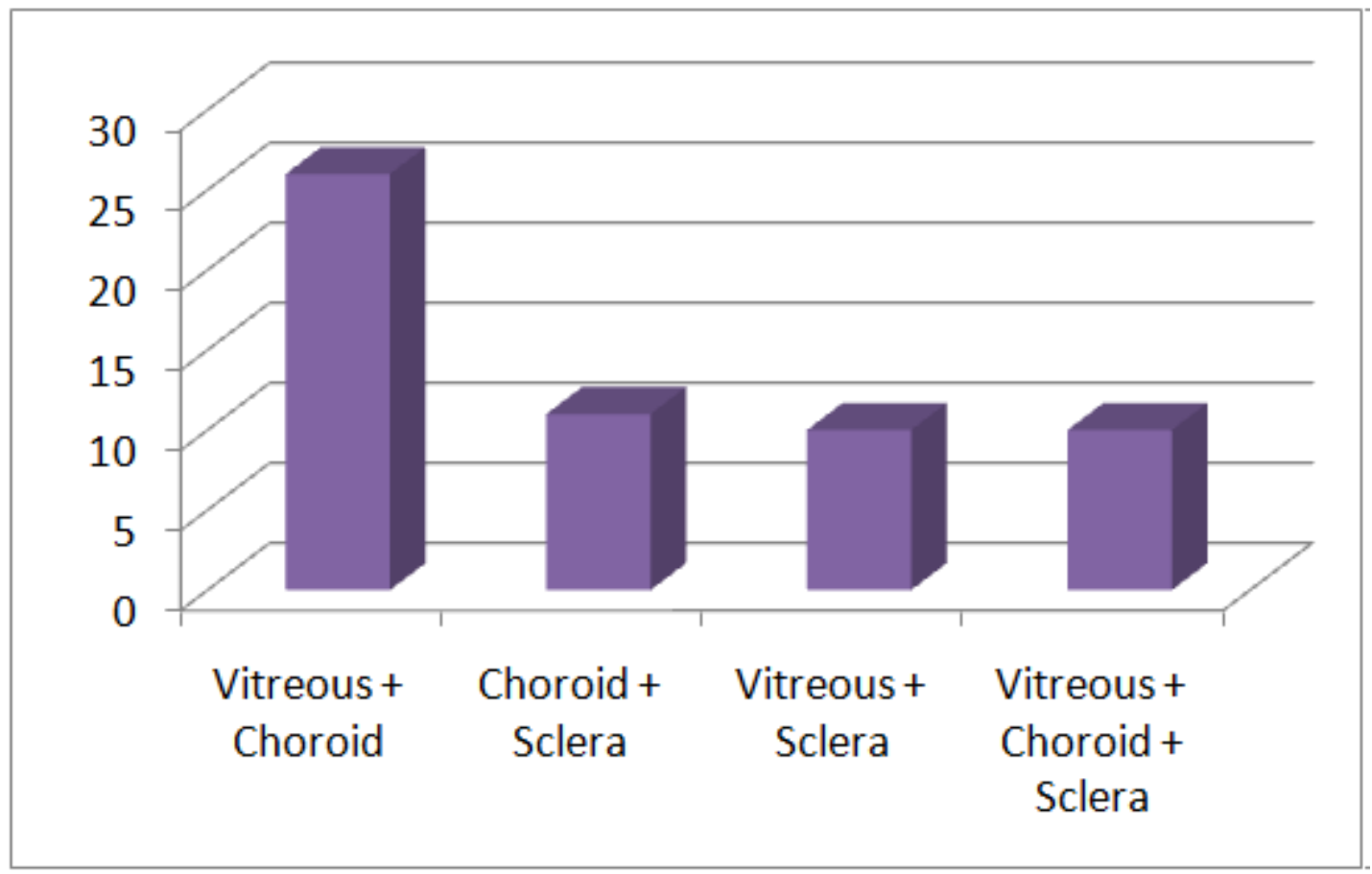

Figure No. 2

Volume 5 Issue 1, January 2016

www.jijs.net 


\section{International Journal of Science and Research (IJSR) \\ ISSN (Online): 2319-7064}

Index Copernicus Value (2013): 6.14 | Impact Factor (2014): 5.611

\section{Discussion}

Retinoblastoma is a primary malignant neoplasm of the retina that arises from immature retinal cells. Retinoblastoma with vitreous seeding has been one of the most challenging conditions for eye-preservation therapy. Several modalities for treating vitreous seeding were reviewed in order to analyze the problems associated with them. External beam radiotherapy has been the most reliable method to treat vitreous seeding. However, recurrence after external beam radiotherapy needs other types of treatments to preserve the eyeballs. Due to the progress of investigations concerning retinoblastoma, chemotherapy has become the most promising method to cure not only recurrence but also primary tumors. Systemic chemotherapy can rarely cure vitreous seeding, but local chemotherapy using vitreous injections of melphalan can preserve about $50 \%$ of the eyeballs with vitreous seeding. Currently, animal experiments are being conducted to study the efficacy and safety of vitreous surgery combined with infusion of anticancer drugs for eradication of vitreous seeds and maintenance of visual function. Thus, study of vitreous, sclera and choroidal involvement is important for management of retinoblastoma patients.

\section{Limitations of Our Study}

We conducted study for 2 years at tertiary care centre. So, we could include patients coming to our institute only. We studied vitreous, choroid and scleral involvement only in enucleated eyes of patients.

\section{Conclusion}

Choroid involvement is most common in retinoblastoma patients.Scleral involvement is least common.Vitreous + choroid involvement is seen in maximum number of patients.

\section{References}

[1] Abramson DH, Schefler AC: Update on retinoblastoma.

[2] Reese AB, Ellsthworth RM. Evaluation and current concept of retinoblastoma therapy. Tr Am AcadOphth 1963; 67:164-72.

[3] JR, Sagerman RH, Tretter P, Ellsthworth RM. Radiation therapy in retinoblastoma. Radiology 1969; 93:405-9.

[4] Abramson DH, Ellsthworth RM, Tretter P, Adams K, Kitchin FD. Simultaneous bilateral radiation for advanced bilateral retinoblastoma. Arch Ophthalmol1981; 99:1763-6.

[5] Baud O, Cormier-Daire V, Lyonnet S, Desjardins L, Turleau C, Doz F: Dysmorphic phenotype and neurological impairment in 22 retinoblastoma patients with constitutional cytogenetic $13 \mathrm{q}$ deletion.

[6] Shields CL, Shields JA, De Potter P, Minelli S, Hernandez C, Brady LW, et al. Plaque radiotherapy in the management of retinoblastoma. Ophthalmology1993; 100:216-24.
[7] Knudson AG Jr: Mutation and cancer: statistical study of retinoblastoma. ProcNatlAcadSci USA 1971, 68:820-823.

[8] Madreperla SA, Hungerford JL, Doughty D, Plowman PN, Kingston JE, Singh AD. Treatment of retinoblastoma vitreous base seeding. Ophthalmology 1998; 105:120-4.

[9] Gallie BL, Bunding A, DeBoer G, Thiessen JJ, Koren G, Verjee Z, et al. Chemotherapy with focal therapy can cure intraocular retinoblastoma without radiotherapy. Arch Ophthalmol 1996; 114:1321-8.

[10] Friend SH, Bernards R, Rogelj S, Weinberg RA, Rapaport JM, Albert DM, Dryja TP: A human DNA segment with properties of the gene that predisposes to retinoblastoma and osteosarcoma.

[11]Kingston JE, Hungerford JL, Madreperla SA, Plowman PN. Results of combined chemotherapy and radiotherapy for advanced intraocular retinoblastoma. Arch Ophthalmol 1996; 114:1339-43.

[12] Murphree AL, Villablanca JG, Deegan III WF, Sato JK, Malogorolowkin M, Fisher A, et al. Chemotherapy plus local treatment in the management of intraocular retinoblastoma. Arch Ophthalmol 1996; 114:1348-56.

[13]Zhang J, Schweers B, Dyer MA: The first knockout mouse model of retinoblastoma, Cell Cycle 2004, 3:952-959.

[14]Ericson LA, Rosengren BH. Present therapeutic resources in retinoblastoma. ActaOphthalmol 1961; 39:569-76.

[15]Zielinski B, Gratias S, Toedt G, Mendrzyk F, Stange DE, Radlwimmer B, Lohmann DR, Lichter P: Detection of chromosomal imbalances in retinoblastoma by matrix-based comparative genomic hybridization.

[16] Ericson LA, Kalberg B, Rosengren BH. Trials of intravitreal injections of chemotherapeutic agents in rabbits. ActaOphthalmol 1964; 42:721-6.

[17] Karpe G. Apparatus and method for clinical recorded of the electroretinogram. DocumOphth 1948; 2: 26876 .

[18] Seregard S, Kock B, afTrampe E. Intravitreal chemotherapy for recurrent retinoblastoma in an only eye. Br J Ophthalmol 1995; 79:194-5.

[19] Inomata M, Kaneko A. Chemosensitivity profiles of primary and cultured retinoblastoma cells in a human tumor clonogenic assay. Jpn J Cancer Res1987; 78:858-68.

[20] Hamburger AW, Salmon SF. Primary bioassay of human tumor stem cells. Science 1977;197:461-3 